\title{
Investigation on structural, spectral, and thermal properties of L-histidinium glutarate monohydrate (LHG)
}

\author{
Helen Merina Albert • A. Joseph Arul Pragasam • \\ G. Bhagavannarayana $\cdot$ C. Alosious Gonsago
}

Received: 6 January 2014 / Accepted: 30 June 2014/Published online: 7 September 2014

(c) Akadémiai Kiadó, Budapest, Hungary 2014

\begin{abstract}
L-histidinium glutarate monohydrate, an organic nonlinear optical crystal has been successfully grown from deionized water by slow solvent evaporation method at room temperature. Crystal structure and its lattice parameters were identified by single-crystal X-ray diffraction technique. Crystalline perfection of the grown crystal was studied by high-resolution X-ray diffraction rocking curve measurements by employing a multicrystal X-ray diffractometer. FT-IR and FT-Raman spectral studies were employed to identify the presence of various functional groups and mode of vibrations in the crystal. Thermal behavior of the crystal was studied by TG-DTA, TG-DTG, and DSC analyses. Optical absorption of the crystal in the wavelength region 200-1,000 nm was studied by UV-Vis-NIR spectral analysis. Kurtz and Perry powder technique was employed to find the second harmonic generation efficiency of the crystal.
\end{abstract}

Keywords XRD $\cdot$ HRXRD - FT-IR - FT-Raman · TG $\cdot$ DTA $\cdot$ DSC

H. M. Albert · A. Joseph Arul Pragasam

Department of Physics, Sathyabama University,

Chennai 600119, India

G. Bhagavannarayana

Materials Characterization Division, National Physical

Laboratory, New Delhi 110012, India

C. A. Gonsago $(\square)$

Department of Physics, A. J. College of Engineering,

Chennai 603103, India

e-mail: dralosious@gmail.com

\section{Introduction}

Crystals are occupying a major part in the areas of modern technology involving lasers, sensors, infrared detectors, optical components, and electrical devices. Recently, there has been a significant advancement toward the investigation and growth of new type of noncentrosymmetric crystalline materials that could generate green/blue laser beam. It is of great interest from both scientific and technological points of view to synthesize such variety of crystals. A large class of nonlinear optical crystals has been synthesized and studied, owing to their significant impact and applications in a wide range of fields like electro-optic modulation, image manipulation, high-resolution printing, and signal processing [1-3]. Practically, organic crystals are the subject of intense research due to the fact that they have high nonlinearity and large electro-optic coefficient with low frequency dispersion compared with the inorganic counterparts. In recent years, a number of organic nonlinear optical salts with promising NLO properties have been synthesized [4-6]. Of these types of crystals, amino acid complexes are suitable materials for nonlinear optical applications due to their dipolar nature [7-10].

The salts of basic amino acid L-histidine gained a great deal of interest as promising nonlinear optical crystals after the discovery of L-histidine tetrafluoroborate by Marcy et al. [11]. It has been reported that the nonlinear optical efficiency of L-histidine tetrafluoroborate is much superior to that of KDP sample. The optically active basic amino acid L-histidine is characterized among the amino acids by the presence of the imidazole ring. In order to synthesis novel crystals with enhanced thermal, electrical, and optical properties, the complexes of L-histidine with dicarboxylic acids have been synthesized and analyzed $[12,13]$. In the present work, Lhistidinium glutarate monohydrate (LHG), an organic crystal has been grown as a possible nonlinear optical crystal for 
second harmonic generation. This paper describes the crystal growth, structural, spectroscopic, thermal, and optical properties of LHG crystal.

\section{Experimental}

Synthesis

The single crystal of L-histidinium glutarate monohydrate (L-His ${ }^{+} \cdot \mathrm{C}_{5} \mathrm{H}_{7} \mathrm{O}_{3}^{-} \cdot \mathrm{H}_{2} \mathrm{O}$ ) has been grown from deionized water by slow evaporation method at $32{ }^{\circ} \mathrm{C}$. The title compound was synthesized by dissolving suitable amounts of L-histidine (Aldrich) and glutaric acid (e-Merk) in deionised water taken in the molar ratio of $1: 1$. The chemical reaction which took place in the deionised water is given below:

$$
\begin{aligned}
& \mathrm{C}_{6} \mathrm{H}_{9} \mathrm{~N}_{3} \mathrm{O}_{2}+\mathrm{C}_{5} \mathrm{H}_{8} \mathrm{O}_{4}+\mathrm{H}_{2} \mathrm{O} \\
& \rightarrow \mathrm{C}_{6} \mathrm{H}_{10} \mathrm{O}_{2} \mathrm{~N}_{3}^{+} \cdot \mathrm{C}_{5} \mathrm{H}_{7} \mathrm{O}_{4}^{-} \cdot \mathrm{H}_{2} \mathrm{O}
\end{aligned}
$$

The solution was slowly heated to dryness at a suitable temperature $<50{ }^{\circ} \mathrm{C}$ to avoid any possible degradation of the substance. The substance was purified further by repeated recrystallization process and used for the growth of single crystal.

\section{Crystal growth}

The purified salt of LHG was thoroughly dissolved in the deionised water to get a clear solution. It was then filtered twice and placed in a crystallizing jar, covered with a perforated sheet and kept in a dust-free atmosphere. Due to continuous evaporation of solvent, the mother solution gradually reached supersaturation. Seed crystals free from macro defects obtained by spontaneous nucleation were used for further growth process. Optically transparent single crystals of LHG were harvested within a period of 25 days. The photograph of LHG is presented in Fig. 1.

\section{Measurements}

The crystal structure and lattice parameters of LHG were identified by the single-crystal X-ray crystallography technique using BRUKER Kappa Apex 2CCD diffractometer with MoK $\alpha$ radiation source of wavelength $0.71073 \AA$ Á. The crystalline perfection of the grown single crystal was characterized by high-resolution X-ray diffraction (HRXRD) by employing a multicrystal X-ray diffractometer. FT-IR spectral analysis was carried out in the region $400-4000 \mathrm{~cm}^{-1}$ using PerkinElmer spectrometer and $\mathrm{KBr}$ pellet technique. FT-Raman spectral analysis was carried out using the instrument Bruker RFS-27 FT-Raman spectrometer. An Nd:YAG air-cooled diode pumped laser beam of power $100 \mathrm{~mW}$ was focused on to

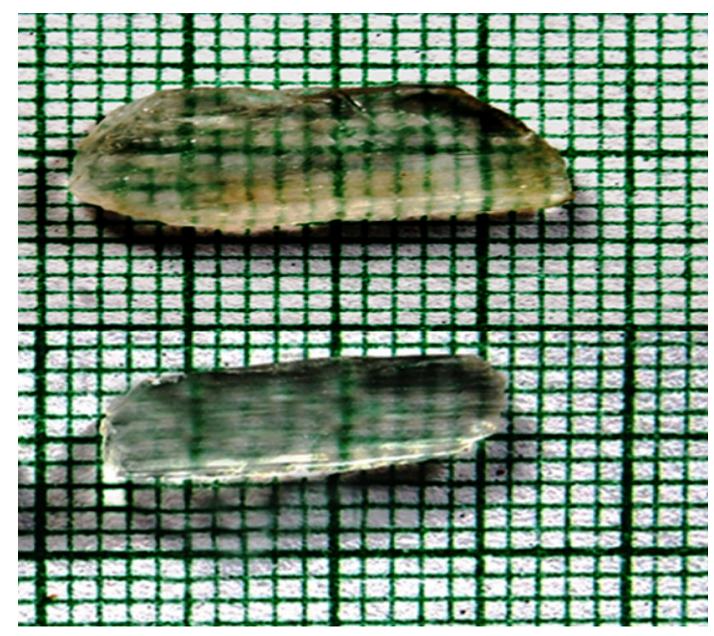

Fig. 1 Photograph of LHG crystals

the sample. The scattered light was collected at the angle of $180^{\circ}$ in the region $200-3,500 \mathrm{~cm}^{-1}$ with a resolution of $2 \mathrm{~cm}^{-1}$ and 224 scans. TG-DTA and TG-DTG studies were performed using Perkin-Elmer thermal analyzer in the temperature range $40-850{ }^{\circ} \mathrm{C}$ at a heating rate of $20{ }^{\circ} \mathrm{C} \mathrm{min}-1$. The DSC analysis was employed in the temperature range 20-200 ${ }^{\circ} \mathrm{C}$ at a heating rate of $10{ }^{\circ} \mathrm{C} \min ^{-1}$ under nitrogen atmosphere using Perkin-Elmer thermal analyzer. The UVVis-NIR absorption spectrum was recorded for the LHG crystal in the wavelength region 200-1,000 nm using a Varian Carry-5E UV-Vis-NIR spectrophotometer. Kurtz powder SHG instrument was used for SHG testing. A Q-switched Nd:YAG laser operated at a fundamental wavelength $1,064 \mathrm{~nm}$ with the input power of $0.68 \mathrm{~J}$, pulse width $8 \mathrm{~ns}$, and pulse rate $10 \mathrm{~Hz}$ was used for SHG measurements.

\section{Results and discussion}

Single-crystal XRD analysis

The X-ray crystallographic data show that the title compound crystallizes in orthorhombic system with the space group $P 2{ }_{1} 2_{1} 2_{1}$. The lattice parameters are $a=8.3259(5) \AA$, $b=8.8462(5) \AA, \quad c=19.4953(9) \AA, \alpha=\beta=\gamma=90^{\circ}$, and $V=1,435.88(14) \AA^{3}$. The observed values of lattice parameters and crystal system are in concurrence with the previously reported data [14]. The single-crystal XRD data of LHG are presented in Table 1.

HRXRD analysis

The HRXRD curve recorded for the typical LHG single crystal specimen is shown in Fig. 2. As observed in the figure, the curve does not seem to be a single peak. The solid line (convoluted curve) is well fitted with the 
Table 1 Crystallographic data for LHG

\begin{tabular}{ll}
\hline Empirical formula & $\mathrm{C}_{11} \mathrm{H}_{19} \mathrm{~N}_{3} \mathrm{O}_{7}$ \\
Formula weight & 305.29 \\
Wavelength & $0.71073 \AA$ \\
Crystal system & Orthorhombic \\
space group & $P 2{ }_{1} 2{ }_{1} 2_{1}$ \\
Unit cell dimensions & $a=8.3259(5) \AA, \alpha=90^{\circ}$ \\
& $b=8.8462(5) \AA, \beta=90^{\circ}$ \\
& $c=19.4953(9) \AA, \gamma=90^{\circ}$ \\
Volume & $1,435.88(14) \AA^{3}$ \\
$Z$ & 4 \\
\hline
\end{tabular}

experimental points represented by the filled circles. On deconvolution of the diffraction curve, it is very clear that the curve contains an additional peak, which is 34 arc s away from the higher intensity peak. The additional peak corresponds to an internal structural very low angle boundary. For a better understanding, the schematic of a structural grain boundary is given in the inset of Fig. 2. As seen in the inset, two regions of the crystal are misoriented by a finite angle $\alpha$ also known as tilt angle. If the value of $\alpha$ is $\leq 1$ arc min, one may call it as very low angle boundary. If $\alpha>1$ arc min but less than a degree, it may be termed as low angle boundary. For more details of such structural grain boundaries including their effect on physical properties, reference is made available elsewhere $[15,16]$. The angular separation between the two peaks gives the tilt angle $\alpha$ which is 34 arc s for the specimen crystal as seen in the figure. The FWHM (full width at half maximum) of the main peak and the low angle boundary are, respectively, 8-48 arc s. These relatively lower values reveal the fact that both the regions of the crystal are nearly perfect. These

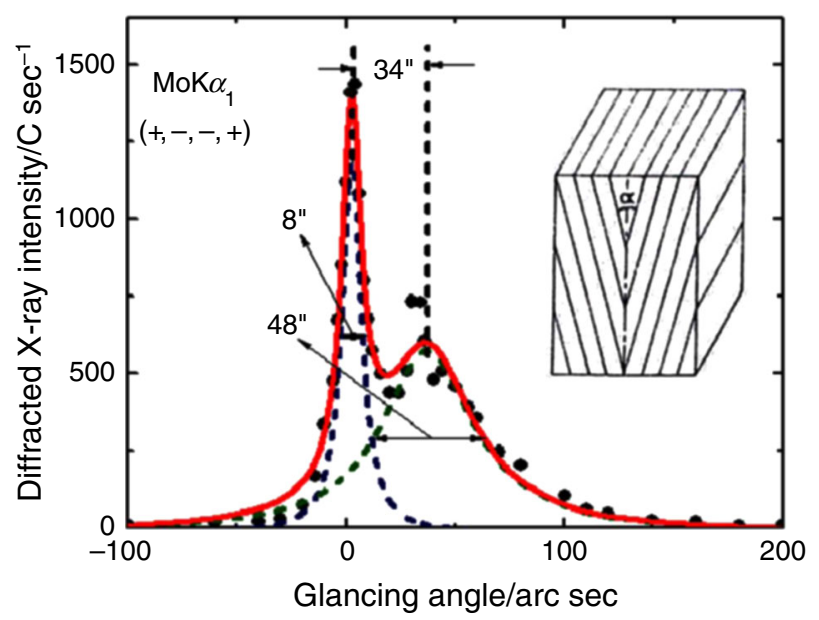

Fig. 2 Diffraction curve recorded for LHG crystal by employing multicrystal X-ray diffractometer. Inlet shows a schematic of a structural grain types of structural defects are probably generated in the crystals due to mechanical/thermal fluctuations occurred during the growth process and/or also due to fast growth [17]. It may be mentioned here that such minute defects could be detected with well-resolved peaks in the diffraction curve only because of the high resolution of the diffractometer, characterized by very low values of the wavelength spread i.e., $\Delta \lambda / \lambda$ and horizontal divergence for the incident beam, which are, respectively, around $10^{-5}$ and much $<3$ arc s of the multicrystal X-ray diffractometer used in the present studies. The influence of such defects may not influence much on the NLO properties. However, a quantitative analysis of such unavoidable defects is of great importance, particularly in the case of phase matching applications as explained in our recent article [18].

Vibrational spectral analysis

FT-IR and FT-Raman studies are very useful techniques for qualitative analysis and identification of compounds. The recorded FT-IR and FT-Raman spectra of LHG are depicted in Figs. 3 and 4.

The spectral bands are interpreted and compared with the standard spectra of the functional groups $[19,20]$. The bands which appear in the spectral region $200-3,500 \mathrm{~cm}^{-1}$ arise from the internal vibrations of $\mathrm{L}$-histidinium cations, glutarate anions, and water molecules, the vibrations of $\mathrm{N}-$ $\mathrm{H} . . . \mathrm{O}$ and $\mathrm{O}-\mathrm{H} . . . \mathrm{O}$ types of hydrogen bonds and also from the lattice vibrations. In the high frequency region of IR spectra, the sharp peaks observed at 3,485 and 3,377 $\mathrm{cm}^{-1}$ are ascribed to asymmetric and symmetric stretching vibrations of water molecule in the crystal. Their Raman equivalents are not observed due to insufficient detector sensitivity in the region above $3,300 \mathrm{~cm}^{-1}$. An intensive IR band assigned to the in-plane bend vibration is observed at $1,623 \mathrm{~cm}^{-1}$ with equivalent Raman band at $1,629 \mathrm{~cm}^{-1}$. It

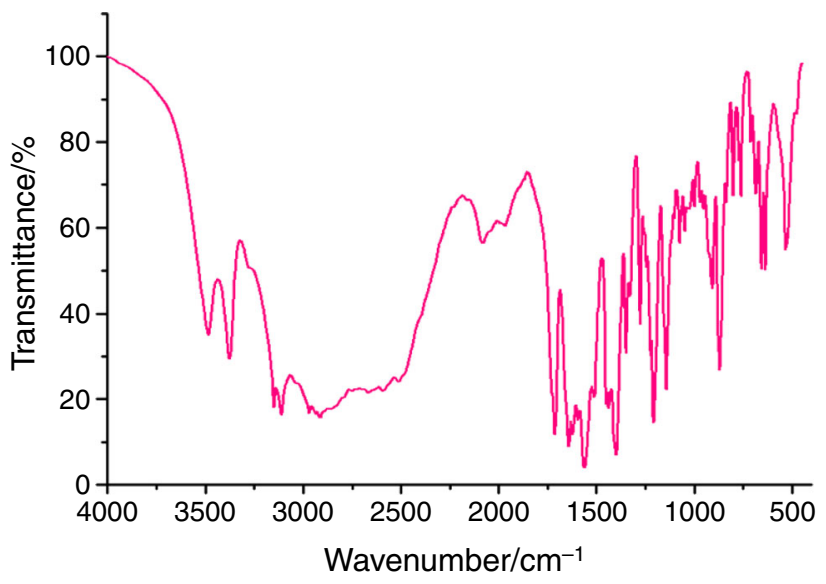

Fig. 3 FT-IR spectrum of LHG 


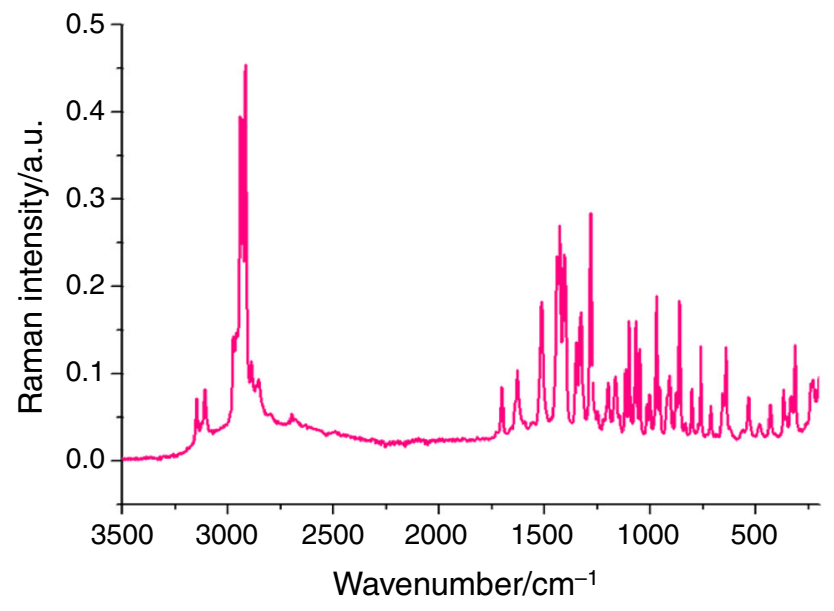

Fig. 4 FT-Raman spectrum of LHG

is observed that some of the bands originate from both Lhistidinium and glutarate ions, simultaneously. The IR band at $2,970 \mathrm{~cm}^{-1}$ is assigned to $\mathrm{C}-\mathrm{H}$ asymmetric stretching vibration, whereas its Raman counterpart is located at $2,976 \mathrm{~cm}^{-1}$ as a weak band. The IR bands at 2,935 and 2,914 $\mathrm{cm}^{-1}$ are assigned to $\mathrm{CH}_{2}$ asymmetric and symmetric stretching vibrations. Their Raman counterparts are resolved at 2,934 and $2,920 \mathrm{~cm}^{-1}$ as strong bands. The weak bands at 2,668, 2,512, 2,082, and $1,968 \mathrm{~cm}^{-1}$ in IR spectrum are due to overtones and combination modes. The amino group of L-histidinium cation is protonated. The peaks at 3,151 and $3,111 \mathrm{~cm}^{-1}$ both in IR and Raman spectra are ascribed to the presence of asymmetric and symmetric stretching vibrations of $\mathrm{NH}_{3}{ }^{+}$group. The strong IR band at $1,714 \mathrm{~cm}^{-1}$ and weak Raman band at $1,704 \mathrm{~cm}^{-1}$ are due to $\mathrm{C}=\mathrm{O}$ stretching vibration of one of the glutarate anion which is not ionized. The IR bands at 1,623 and $1,439 \mathrm{~cm}^{-1}$ are assigned to asymmetric and symmetric stretching vibration of ionized carboxylate group. In Raman spectrum, these bands appear at 1,629 and $1,442 \mathrm{~cm}^{-1}$, respectively. The bands at $1,103 \mathrm{~cm}^{-1}$ (IR) and $1,101 \mathrm{~cm}^{-1}$ (Raman) are assigned to ring asymmetric stretch, while the bands at $906 \mathrm{~cm}^{-1}$ (IR) and $907 \mathrm{~cm}^{-1}$ (Raman) are assigned to ring symmetric stretching vibrations. In IR spectrum, the bands at 1,595 and $1,278 \mathrm{~cm}^{-1}$ are attributed to aromatic $\mathrm{C}=\mathrm{C}$ and $\mathrm{C}-\mathrm{C}$ stretching vibrations, while in the Raman spectrum the aromatic $\mathrm{C}-\mathrm{C}$ stretching is resolved at $1,282 \mathrm{~cm}^{-1}$. The IR band at $1,076 \mathrm{~cm}^{-1}$ is ascribed to $\mathrm{C}-\mathrm{N}$ stretching vibration, and its Raman counterpart is located at $1,069 \mathrm{~cm}^{-1}$. In the IR spectrum, a number of intense bands are also found in the frequency region $1,320-1,050 \mathrm{~cm}^{-1}$, which are due to $\mathrm{C}-\mathrm{O}$ stretching vibrations and the peaks at 1,246, 1,209, and $1,144 \mathrm{~cm}^{-1}$ can be attributed to this kind of vibrations. The important bands that support our interpretation are listed in Table 2.
Table 2 FT-IR and FT-Raman frequency assignments for LHG

\begin{tabular}{|c|c|c|}
\hline \multicolumn{2}{|c|}{ Wavenumber $/ \mathrm{cm}^{-1}$} & \multirow[t]{2}{*}{ Assignment } \\
\hline IR & Raman & \\
\hline 3485 & & $\mathrm{H}_{2} \mathrm{O}$ asymmetric stretch \\
\hline 3377 & & $\mathrm{H}_{2} \mathrm{O}$ symmetric stretch \\
\hline 3151 & 3151 & $\mathrm{NH}_{3}{ }^{+}$asymmetric stretch \\
\hline 3111 & 3111 & $\mathrm{NH}_{3}{ }^{+}$symmetric stretch \\
\hline 2970 & 2976 & $\mathrm{C}-\mathrm{H}$ asymmetric stretch \\
\hline 2935 & 2933 & $\mathrm{CH}_{2}$ asymmetric stretch \\
\hline 2914 & 2920 & $\mathrm{CH}_{2}$ symmetric stretch \\
\hline 2512 & & Overtones and combination \\
\hline 2082 & & Overtones and combination \\
\hline 1714 & 1704 & $\mathrm{C}=\mathrm{O}$ stretch \\
\hline 1643 & & $\mathrm{NH}_{3}{ }^{+}$asymmetric bend, $\mathrm{C}-\mathrm{C}$ stretch \\
\hline 1623 & 1629 & $\mathrm{COO}^{-}$asymmetric stretch \\
\hline 1595 & & Aromatic $\mathrm{C}=\mathrm{C}$ stretch \\
\hline 1562 & & $\mathrm{COO}^{-}$asymmetric stretch \\
\hline 1515 & 1515 & $\mathrm{NH}_{3}{ }^{+}$symmetric bend \\
\hline 1439 & 1442 & $\mathrm{COO}^{-}$symmetric stretch \\
\hline 1400 & 1407 & $\mathrm{C}-\mathrm{H}$ bend \\
\hline 1351 & 1350 & $\mathrm{CH}_{2}$ twist \\
\hline 1278 & 1282 & Aromatic $\mathrm{C}-\mathrm{C}$ stretch \\
\hline 1246 & & $\mathrm{C}-\mathrm{O}$ stretch \\
\hline 1209 & & $\mathrm{C}-\mathrm{O}$ stretch \\
\hline 1144 & & $\mathrm{C}-\mathrm{O}$ stretch \\
\hline 1103 & 1101 & Ring asymmetric stretch \\
\hline 1076 & 1069 & $\mathrm{C}-\mathrm{N}$ stretch, $\mathrm{C}-\mathrm{C}-\mathrm{O}$ asymmetric stretch \\
\hline 1000 & 1004 & $\mathrm{~N}-\mathrm{H}$ deformation \\
\hline 908 & 909 & Ring symmetric stretch \\
\hline 871 & 879 & $\mathrm{C}-\mathrm{C}-\mathrm{O}$ sym stretch \\
\hline 762 & 762 & Ring deformation \\
\hline 658 & 659 & $\mathrm{C}=\mathrm{O}$ deformation \\
\hline 534 & 535 & $\mathrm{C}-\mathrm{C}-\mathrm{O}$ in-plane bend \\
\hline
\end{tabular}

Thermal studies

TG-DTA, TG-DTG, and DSC studies were employed to find the water of crystallization, phase transition, and thermal decomposition of the compound. The simultaneously recorded TG-DTA and TG-DTG traces of LHG are shown in Figs. 5 and 6. The TG trace shows different stages of decomposition of the compound. It shows a gradual and small mass loss in the temperature range $100-185^{\circ} \mathrm{C}$, which is ascribed to the removal of weakly entrapped lattice water from the crystal. The total mass loss observed in this stage is about $6.85 \%$, and this corresponds to the loss of one water molecule from the substance. The DTG trace shows a clear inflexion point at this stage, and the DTA curve shows a sharp endothermic peak at around $110{ }^{\circ} \mathrm{C}$, which is due to the removal of water molecule from the crystal. 


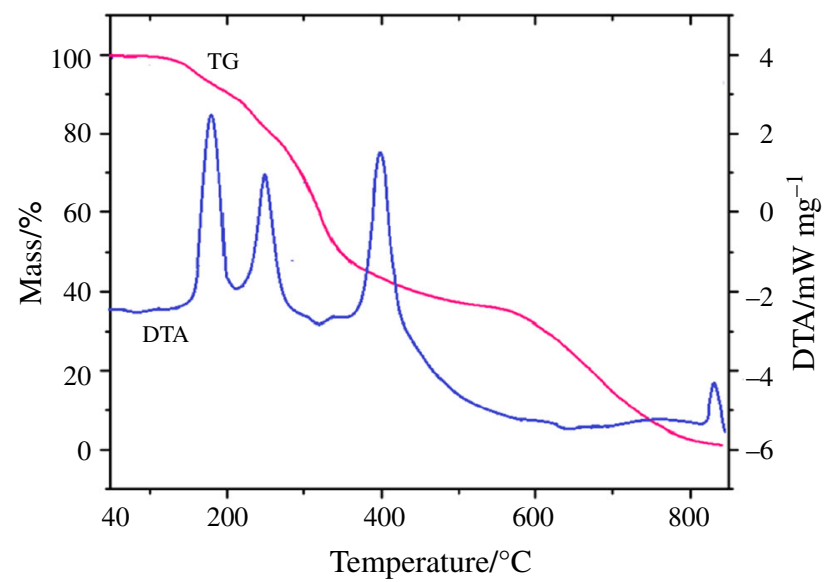

Fig. 5 TG-DTA traces of LHG

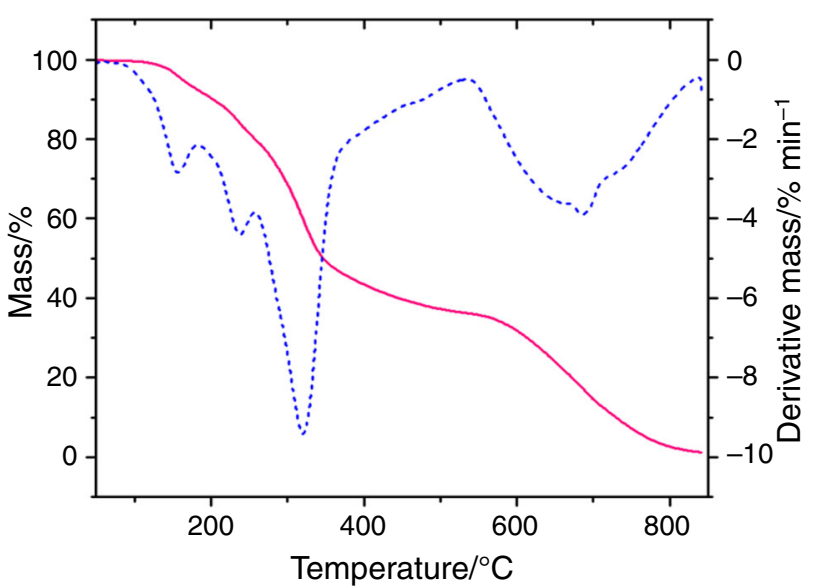

Fig. 6 TG-DTG traces of LHG

In the second stage, $\mathrm{TG}$ curve shows a gradual mass loss of about $13.2 \%$ occurring between 185 and $260{ }^{\circ} \mathrm{C}$ which is ascribed to the decomposition of the glutarate ions. The DTG curve shows an inflexion point which is in good agreement with the TG trace. During this stage, the DTA curve shows an intensive sharp endotherm at $190{ }^{\circ} \mathrm{C}$. In the third stage, TG curve shows a mass loss of compound (36.15\%) occurring between 260 and $400{ }^{\circ} \mathrm{C}$ which corresponds to the degradation of L-histidinium ions. During this stage, the DTA trace shows a sharp endotherm at $260{ }^{\circ} \mathrm{C}$ which matches very well with the DTG trace.

During the last stage of decomposition, the TG curve shows a major mass loss of about $42.3 \%$ occurring between 400 and $840{ }^{\circ} \mathrm{C}$ which indicates complete decomposition of the compound and removal of residual products. The DTA curve shows a sharp endotherm at around $550{ }^{\circ} \mathrm{C}$. DTG trace reveals the same changes shown by DTA trace. The initial mass of the compound subjected

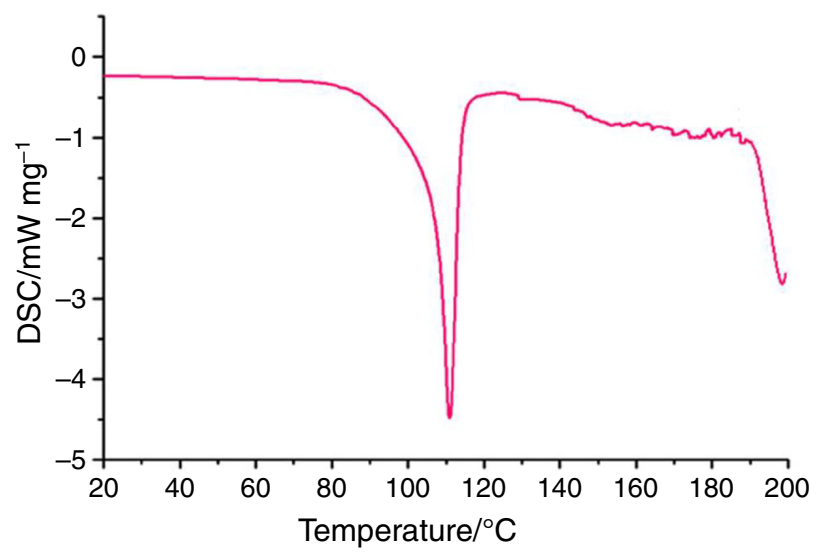

Fig. 7 DSC trace of LHG

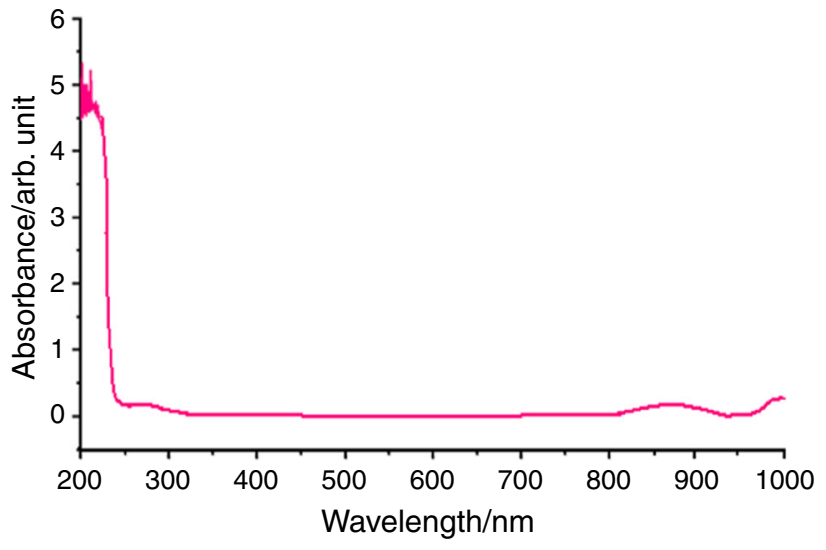

Fig. 8 UV-Vis-NIR spectrum of LHG

for the analysis was $3.033 \mathrm{mg}$, and the final mass left out after the analysis was only $1.5 \%$ of the initial mass and this shows bulk decomposition of the compound.

The typical DSC trace of LHG is shown in Fig. 7. The DSC trace is smooth up to $90{ }^{\circ} \mathrm{C}$, and then shows a sharp endothermic peak at $110{ }^{\circ} \mathrm{C}$ which is ascribed to the removal of weakly entrapped water from the crystal lattice. This is followed by another peak with the onset temperature of $190{ }^{\circ} \mathrm{C}$ which indicates the decomposition of the compound. From the DTA and DSC traces, it is evident that the sample melts or decomposes at $110^{\circ} \mathrm{C}$.

\section{UV-Vis-NIR study}

In order to find the usefulness of the grown crystal for optical applications, UV-Vis-NIR absorption study was performed. Optical absorption spectrum of LHG is depicted in Fig. 8. The spectrum clearly reveals that the optical 
absorption for the given crystal is almost negligible in the near UV and visible spectral regions. The lower cut-off wavelength of the crystal is found to be $235 \mathrm{~nm}$. Complete optical transparency of the crystal in the near UV and visible spectral regions with the lower cut-off wavelength of $235 \mathrm{~nm}$ suggest that the LHG can be used as a possible material for optical applications.

\section{Kurtz and Perry SHG test}

The second harmonic generation conversion efficiency of grown compound was tested by powder technique of Kurtz and Perry [21]. The generation of second harmonic signal has been identified by the emission of green light (532 nm) from the LHG sample. Powdered sample of KDP has been used as the reference material for SHG efficiency comparison. The second harmonic generation signal of $6.5 \mathrm{~mJ}$ was obtained from LHG sample, whereas the standard KDP sample gave an SHG signal of $8.9 \mathrm{~mJ}$ for the same input energy. Thus, it has been observed that the SHG efficiency of the LHG crystal is 0.73 times that of the standard KDP crystal.

\section{Conclusions}

L-histidinium glutarate monohydrate (LHG), an organic nonlinear optical material has been synthesized and grown by slow solvent evaporation method at the room temperature of $32{ }^{\circ} \mathrm{C}$. Single-crystal XRD data indicate that the LHG crystal belongs to orthorhombic system with $P 2{ }_{1} 2_{1} 2_{1}$ space group. The HRXRD study confirms the crystalline perfection with an internal structural very low angle boundary. The FT-IR and FT-Raman spectral studies confirm the presence of L-histidinium cations and glutaric anions in the compound. Thermal studies indicate that the LHG crystal is thermally stable up to $110{ }^{\circ} \mathrm{C}$ and could be used as a possible material for photonics applications below this temperature. Kurtz and Perry powder technique shows the SHG efficiency of the LHG sample to be 0.73 times that of KDP sample. The above studies substantiate the suitability of LHG crystal for photonic applications.

\section{References}

1. Gonsago CA, Albert HM, Malliga P, Pragasam AJA. Crystallization, spectral, and thermal characterization of L-histidine methyl ester dihydrochloride (LHMED). J Therm Anal Calorim. 2012;107:1231-5.

2. Ezhil Vizhi R, Ashok Kumar R, Sathiyanarayanan K, Vijayan N, Bhagavannarayana G, Rajan Babu D. Structural and mechanical studies of semi-organic NLO material: zinc thiourea chloride. Mater Manuf Process. 2012;27:53-7.
3. Prabha K, Feng B, Chen H, Bhagavannarayana G, Sagayaraj P. Growth and characterization of a new non-linear optical tris lead tris barium borate (TLTBB) single crystal. Mater Chem Phys. 2011;127:79-84.

4. Anbusrinivasan P, Madhurambal G, Mojumdar SC. p- $N, N$-dimethylaminobenzaldehyde (DAB) grown by solution technique using CCl4 as growth medium. J Therm Anal Calorim. 2009;96:111-5.

5. Singh S, Lal B. Growth and characterization of a nonlinear optical crystal 2-hydroxy-3-methoxy- $N$-(2-chloro-benzyl)benzaldehyde-imine. J Cryst Growth. 2010;312:301-4.

6. D'silva ED, Krishna Podagatlapalli G, Venugopal Rao S, Dharmaprakash SM. Synthesis, growth and characterization of novel second harmonic nonlinear chalcone crystal. Opt Laser Technol. 2012;44:1689-97.

7. Gonsago CA, Albert HM, Umamaheswari R, Pragasam AJA. Spectral, optical and thermal studies of pure and $\mathrm{Zn}$ (II)-doped Lhistidine hydrochloride monohydrate (LHHC) crystals. J Therm Anal Calorim. 2012;110:839-45.

8. Prakash M, Geetha D, Lydia Caroline M. Crystal growth and characterization of L-phenylalaninium trichloroacetate-a new organic nonlinear optical material. Phys B. 2011;406:2621-5.

9. Chandrasekaran J, Ilayabarathi P, Maadeswaran P, Mohamed Kutty P, Pari S. Growth and characterization of L-histidine cadmium chloride monohydrate a semiorganic nonlinear optical crystals. Opt Commun. 2012;285:2096-100.

10. Sun GH, Sun XT, Sun ZH, Wang XQ, Liu XJ, Zhang GH, Xu D. Growth and characterization of a nonlinear optical crystal: Lhistidine trifluoroacetate. J Cryst Growth. 2009;311:3904-10.

11. Marcy HO, Rosker MJ, Warren LF, Cunningham PH, Thomas CA. L-histidine tetrafluoroborate: a solution-grown semi-organic crystal for nonlinear frequency conversion. Opt Lett. 1995;20:252-4.

12. Gonsago CA, Albert HM, Karthikeyan J, Sagayaraj P, Pragasam AJA. Crystal structure, optical and thermal studies of a new organic nonlinear optical material: L-histidinium maleate-1.5 hydrate. Mater Res Bull. 2012;47:1648-52.

13. De Matos Gomes E, Rodrigues VH, Costa MM, Belsley MS, Cardosco PJM, Gonclves CF, Proenca F. Unusual supramolecular assembly and nonlinear optical properties of L-histidinium hydrogen malate. J Solid State Chem. 2006;179:2521-8.

14. Saraswathi NT, Vijayan M. X-ray studies on crystalline complexes involving amino acids and peptides. XXXVIII. Crystal structures of the complexes of L-arginine and L-histidine with glutaric acid and a comparative study of amino acid-glutaric acid complexes. Acta Crystallogr B. 2001;57:842-9.

15. Bhagavannarayana G, Ananthamurthy RV, Budakoti GC, Kumar B, Bartwal KS. A study of the effect of annealing on Fe-doped $\mathrm{LiNbO}_{3}$ by HRXRD, XRT and FT-IR. J Appl Crystallogr. 2005;38:768-71.

16. Bhagavannarayana G, Kushwaha SK. Enhancement of SHG efficiency by urea doping in ZTS single crystals and its correlation with crystalline perfection as revealed by Kurtz powder and high-resolution X-ray diffraction methods. J Appl Crystallogr. 2005;43:154-62.

17. Bhagavannarayana G, Rajesh P, Ramasamy P. Interesting growth features in potassium dihydrogen phosphate: unravelling the origin and dynamics of point defects in single crystals. J Appl Crystallogr. 2010;43:1372-6.

18. Bhagavannarayana G, Riscob B, Shakir M. Growth and characterization of L-leucine 1-leucinium picrate single crystal: a new nonlinear optical material. Mater Chem Phys. 2011;126:20-3.

19. Bellamy LJ. The infrared spectra of complex molecules. 3rd ed. New York: Wiley; 1975.

20. Herzberg G. Infrared and Raman spectra of polyatomic molecules. 1st ed. New York: Van Nostrand Reinhold; 1945.

21. Kurtz SK, Perry TT. A powder technique for the evaluation of non-linear optical materials. J Appl Phys. 1968;39:3798-813. 